Bond University

Research Repository

\title{
In silico investigation into the interactions between murine 5-HT3 receptor and the principle active compounds of ginger (Zingiber officinale)
}

Lohning, Anna E.; Marx, Wolfgang; Isenring, Liz

Published in:

Journal of Molecular Graphics and Modelling

DOI:

10.1016/j.jmgm.2016.10.008

Licence:

CC BY-NC-ND

Link to output in Bond University research repository.

Recommended citation(APA):

Lohning, A. E., Marx, W., \& Isenring, L. (2016). In silico investigation into the interactions between murine 5-HT 3 receptor and the principle active compounds of ginger (Zingiber officinale). Journal of Molecular Graphics and 3 Modelling, 70, 315-327. https://doi.org/10.1016/j.jmgm.2016.10.008

\section{General rights}

Copyright and moral rights for the publications made accessible in the public portal are retained by the authors and/or other copyright owners and it is a condition of accessing publications that users recognise and abide by the legal requirements associated with these rights.

For more information, or if you believe that this document breaches copyright, please contact the Bond University research repository coordinator 


\section{Abstract}

Gingerols and shogaols are the primary non-volatile actives within ginger (Zingiber officinale). These compounds have demonstrated in vitro to exert 5-HT3 receptor antagonism which could benefit chemotherapy-induced nausea and vomiting (CINV). The site and mechanism of action by which these compounds interact with the $5-\mathrm{HT}_{3}$ receptor is not fully understood although research indicates they may bind to a currently unidentified allosteric binding site. Using in silico techniques, such as molecular docking and GRID analysis, we have characterized the recently available murine $5-\mathrm{HT}_{3}$ receptor by identifying sites of strong interaction with particular functional groups at both the orthogonal (serotonin) site and a proposed allosteric binding site situated at the interface between the transmembrane region and the extracellular domain. These were assessed concurrently with the top-scoring poses of the docked ligands and included key active gingerols, shogaols and dehydroshogaols as well as competitive antagonists (e.g. setron class of pharmacologically active drugs), serotonin and its structural analogues, curcumin and capsaicin, non-competitive antagonists and decoys. Unexpectedly, we found that the ginger compounds and their structural analogs generally outscored other ligands at both sites. Our results correlated well with previous site-directed mutagenesis studies in identifying key binding site residues. We have identified new residues important for binding the ginger compounds. Overall, the results suggest that the ginger compounds and their structural analogues possess a high binding affinity to both sites. Notwithstanding the limitations of such theoretical analyses, these results suggest that the ginger compounds could act both competitively or non-competitively as has been shown for palonosetron and other modulators of CYS loop receptors.

\section{Keywords}

Ginger antiemetic Zingiber officinale gingerol shogaols chemotherapy induced nausea vomiting 


\section{Introduction}

Chemotherapy-induced nausea and vomiting (CINV) poses a major obstacle to patients often resulting in treatment cessation due to its severity and intolerability. Without appropriate antiemetic prophylaxis, up to ninety percent of all cancer patients receiving chemotherapy may experience nausea and/or vomiting.[1] In a recent review of the incidence of CINV, around twenty to forty percent of patients failed to respond to the current antiemetic treatments in relation to either vomiting or nausea with nausea being less well managed.[2] Nausea and delayed CINV are reported as particular challenges in clinical practice. Thus a significant impetus exists to develop more effective treatments.

This study focuses on one of the primary pathways of emesis relating to CINV - the stimulation of vagal afferent nerves due to high levels of serotonin released from the mucosal enterochromaffin cells of the gut.[1, 3, 4] Serotonin allosterically activates the 5-HT Type 3 (or 5-HT3) ion channel by binding to a site distinct from the transmembrane region where channel opening occurs, facilitating neuronal depolarisation.[5]

The cationic 5- $\mathrm{HT}_{3}$ receptor belongs to the CYS loop superfamily of ligand-gated ion channels (LGICs) along with nicotinic acetylcholine receptors (nAchR) and anionic g-aminobutyric acid receptor $\left(\mathrm{GABA}_{\mathrm{A}}\right.$ and $\left.\mathrm{GABA}_{\mathrm{C}}\right)$ and glycine receptor.[6] The function of 5-HT3 receptors is intricately fine-tuned by the binding of other molecules and ions in and adjacent to the channel, either extracellularly or within the membrane region. For example, all CYS-loop receptors are allosterically regulated by zinc ions binding at multiple locations.[7] Both anions and cations can enter the pore where ion filtering is controlled by specific residues lining the narrow region of the pore at the cytoplasmic end of the transmembrane domain (TMD) extending into the TMI-II 
cytoplasmic loop.[8] A second ion filter controlling ion flow has been observed in the 5- $\mathrm{HT}_{3}$ receptor at the intracellular transmembrane TMIII-IV loop.[9]

CYS loop receptors share significant structural similarity consisting of a pentameric assembly of subunits with three domains: N-terminal extracellular domain (ECD) with the 15 amino acid CYS-loop disulphide; transmembrane domain with four helices, MI-IV and intracellular domain (ICD) consisting of a long loop between MIII and MIV (Figure 1). The C-terminus is extracellular.
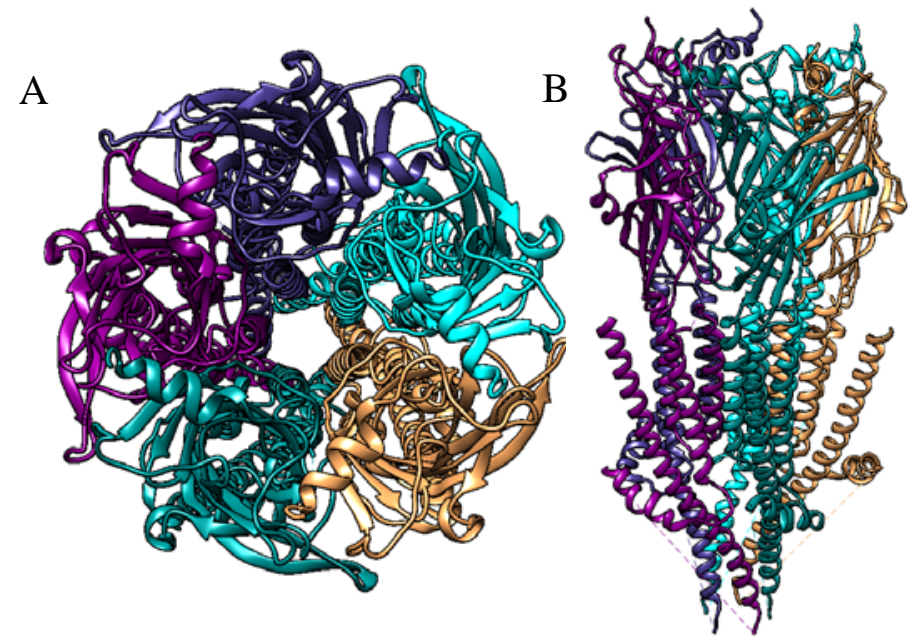

Figure 1. Pentameric subunit arrangement of the $5-\mathrm{HT}_{3}$

receptor extract from PDB entry 4pir. (A): Top view (B):

side view ECD containing (top), alpha helical TM domain

and intracellular domain.

Five distinct subunits (A to E) have been identified for the 5-HT3 receptor whereby A, B, C \& E are similar while subunit 5-HT3D lacks an amino terminal CYS loop.[10] The subunits in the functioning unit are either arranged homo or heteromerically around a cation-specific, water filled central pore. Only the A subunit has been shown to form functional homomeric receptors and, importantly, the presence of the A subunit was required in all receptors. Adding to the functional complexity, heteromeric receptors contain more possible sites for allosteric modulation than 
homomeric receptors.[11] Davies et al.[11] described a kinetic model of the 5-HT3 receptor function delineating between open, closed and desensitized states.

A number of agonists and antagonists have been identified which are able to displace serotonin.[12] Among those that have significantly improved control of CINV are the "setron" class of antiemetics. Ondansetron and granisetron as well as the more recently introduced palonosetron, for example, are important tools not only for CINV but also emesis related to anaesthesia, surgery and radiotherapy.[13-16] Recently observations of multiple modes of inhibition by palonosetron, for example, exhibiting pseudo irreversible inhibition at the serotonin site but also acting at a distinct allosteric site, exemplifies the complexity of modulation and challenges to medicinal chemists.[17-21] This phenomenon has also been established for other CYS loop receptors.

Empirical evidence from in vitro and clinical data suggests ginger (Zingiber officinale) may be an effective treatment against several types of nausea including morning sickness, motion sickness and chemotherapy-induced nausea and vomiting.[22, 23] Gingerols (for example 6G-10G) constitute the principle, non-volatile, pungent components of ginger and have been associated with pharmacological effects including anti-inflammatory, anti-pyretic, angiogenesis, chemopreventive and antioxidant activity.[24, 25]<smiles>COc1cc(CCC(=O)CC(O)CC(C)(C)C)ccc1O</smiles>

6G $(n=2)[6]$-gingerol

8G $(n=3)$ [8]-gingerol

10G $(n=4)[10]$-gingerol<smiles>C=CCC=CC(=O)CCc1ccc(O)c(OC)c1</smiles>

6S (n=2) [6]-shogaol

8S (n=3) [8]-shogaol

$10 S(n=4)$ [10]-shogaol<smiles>CCCCCC(C)C=CC(=O)C=Cc1ccc(O)c(OC)c1</smiles>

6DHSG (n=2) [6]-dehydroshogaol

8DHSG ( $\mathrm{n}=3$ ) [8]-dehydroshogaol

10DHSG ( $\mathrm{n}=4)$ [10]-dehydroshogaol 
These phenols contain an unbranched alkyl chain differing in length. Minor components include the more oxidized shogaols (for example, 6S-10S) or dehydroshogaols (for example, 6DHSG10DHSG). In contrast to the gingerols, both shogaols and dehydroshogaols contain an $\alpha, \beta$ unsaturated carbonyl group (Michael acceptor moiety) known to possess antioxidative activity and chemoprotective effects.[26] The principle compounds in ginger, gingerols and shogaols, have been demonstrated to inhibit serotonin-mediated signaling and that this interaction could be mediated through a currently unidentified binding site.[27][[28, 29] In vitro studies by Abdel Aziz found that 6S, 6G, 8G and 10G inhibited 5- $\mathrm{HT}_{3}$-induced contractions of the isolated guinea-pig ileum. Since these same compounds were unable to displace the competitive antagonist, $\left[{ }^{3} \mathrm{H}\right]$ GR65630, from the serotonin binding site, a non-competitive mechanism was proposed. These results were corroborated by an in vitro study by Walstab et al.[10] which indicated that ginger was able to inhibit the activation of human $5-\mathrm{HT}_{3}$ receptors and that this was likely via noncompetitive mechanisms. Additionally, since pre-incubation with 6G produced increased inhibition it was proposed that its binding site may be relatively inaccessible such as that of the transmembrane channel. As Walstab et al. noted, when combined with standard 5-HT3 antagonists, the non-competitive binding of ginger compounds could potentially provide an additive effect to the control of nausea and vomiting in clinical practice. Indeed, clinical trials have reported a significant improvement in CINV where ginger was combined with standard treatment with a setron class drug.[22, 30]

Recently, the crystal structure of the murine 5- $\mathrm{HT}_{3}$ receptor in the apo (or unbound) form

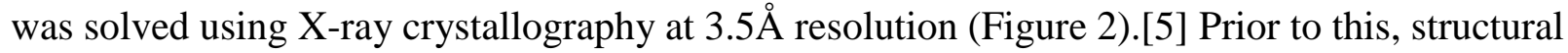
studies had relied on homology models using templates from other CYS loop receptors.[31] 


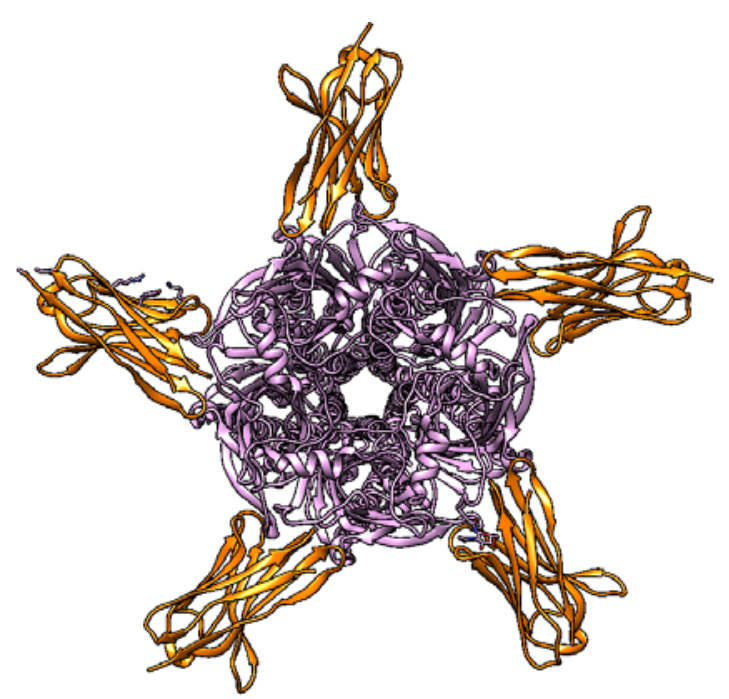

Figure 2. VHH nanobodies (orange) bound to 5-

$\mathrm{HT}_{3}$ receptor ECD (PDB entry: 4pir)

Hassaine et al.[5] found that the binding of the VHH nanobodies resulted in potent inhibition (sub-nanomolar), possibly stabilizing a non-conducting conformation. Despite the relatively low resolution, knowledge of the three-dimensional structure has facilitated these in silico investigations with the aim of investigating the binding characteristics of the primary compounds within ginger on the $5-\mathrm{HT}_{3}$ receptor. In particular, this study compared the binding interactions of gingerols, shogaols and dehydroshogaols at the serotonin site with those at the proposed allosteric binding site. It is hoped that this will provide additional insight into the nature of the binding interactions of these compounds in relation to the 5- $\mathrm{HT}_{3}$ receptor which may improve our understanding of these complex molecular machines and assist development of novel antiemetic agents.

\section{Materials and Methods}

Molecular Modelling

Molecular docking, energy minimizations and structure analyses were performed using SYBYLX version 2.1 distributed by Certara LP (USA) (SYBYL).[32] Sites of strong binding interactions 
were identified using Peter Goodford's GRID software distributed by Molecular Discovery Ltd.[33]

Target and ligand library preparation

Principle and complimentary subunits, A+/A-, were extracted from the pentameric, murine 5$\mathrm{HT}_{3}$ receptor structure 4pir.pdb. Extraneous ligands were removed, hydrogens added and Gasteiger-Huckel charges were assigned to the atoms of both protein and ligands prior to energy minimization (Amber FF99[34]) to a convergence of $0.5 \mathrm{kcal}$ per mol.

Known competitive antagonists, structural analogs to gingerols, non-competitive antagonists and decoys (molecules known not to bind to the $5-\mathrm{HT}_{3}$ receptor) were included in the analysis in order to compare binding characteristics with the ginger compounds.

To assist with interpretation, a number of scatter plots were prepared using physical characteristics of the ligands to look for possible correlations and trends.

\section{Sequence Homology}

A sequence comparison between human and mouse subunits A and B was conducted using ClustalOmega[35] and coloured according to the FASTA[36] scheme.

\section{Molecular Docking}

Docking was performed using the Surflex-Dock 2.1 algorithm.[37] Protomol generation, for the serotonin binding site, was based on a multi-channel approach while a residue-based approach was used at the allosteric binding site. This difference was due to the differences in spatial location of the two sites and the way in which the software defines them. The protomol at each site was generated using a threshold value of 0.5 and 0.9 and a bloat of 10 and 10, respectively to create a protomol which adequately represented each site. 
Surflex-Dock ranks ligands in order of highest binding interaction to lowest by applying scoring functions, taking into account non-bonded interactions between the ligand and target, including hydrophobic, polar, electrostatic, van der Waal and entropic considerations. Consensus scoring ( $\left.\mathrm{C}_{\text {score }}\right)$ calculates scores across all 4 scoring functions. $\mathrm{C}_{\text {scores }}$ are between $0-5$, with a $\mathrm{C}_{\text {score }}$ of 5 reflecting complete consensus of the pose binding score across all scoring functions while a lower score indicating less consensus. The total score is expressed as $-\log K_{D}$ to represent binding affinity. The lower the dissociation constant, $K_{D}$, the stronger the binding. When expressed as $-\log _{D}$ a higher positive value reflects stronger binding.

Total scores comprise the sum of a positive 'polar' contribution and a negative 'crash' score. The 'crash' score denotes the degree of inappropriate penetration of ligand atoms within the binding site while the 'polar' score incorporates the hydrogen bonding and other non-bonded interaction terms. Those ligands that are able to interact strongly to target residue atoms are likely to have higher total scores unless negative steric factors predominate.

Figure 3 depicts the size and orientation of the protomol for the serotonin and allosteric binding sites respectively within which the ligands were docked. Both protomols were checked prior to docking to ensure ligand conformational space were included therein with a reasonable margin. Consensus scoring ( $\left.\mathrm{C}_{\text {score }}\right)$ was included to identify structures obtaining high scores across all 4 scoring functions. $\mathrm{C}_{\text {scores }}$ are between 0-5. A $\mathrm{C}_{\text {score }}$ of 5 reflects complete consensus of the pose binding score across all scoring functions. 
(A)



(B)

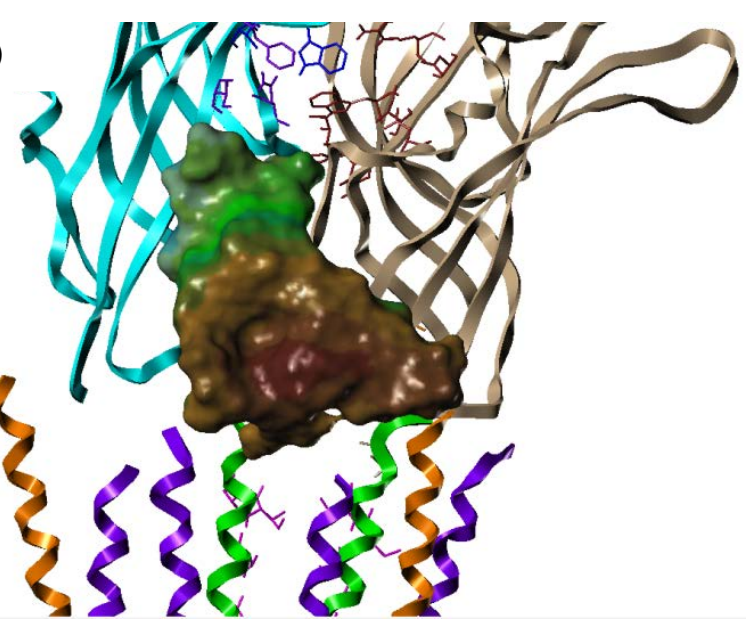

Figure 3. Protomols for serotonin (A) and allosteric (B) binding sites. Connolly surface showing lipophilic character [polar (green) brown (non-polar)].

\section{GRID Analysis}

Grid was used to elucidate potential sites of strong binding interaction between a target and a probe.[38] A number of single and multi-atom probes were selected which best reflected the functional groups of serotonin and the ginger compounds of interest. A box of dimensions (topx,y,z; botx,y,z) was generated around the two sites of interest on the receptor (Supplemental Information Table 1 and 2).

The resolution (number of grid points at which to calculate the interaction energy between probe and target) was set to $(0.33 \AA)$. The LEAU parameter was set to 1 where the probe contained 2 or more hydrogen bond donor/acceptors, otherwise it was 0 . Other settings were left at default values. The probes used are: water $(\mathrm{OH} 2)$, aromatic carbon $(\mathrm{C} 1=)$, methyl carbon (C3), phenolic hydroxyl oxygen (O1), alkyl hydroxyl oxygen (OH), carbonyl oxygen O, hydrophilic (DRY) and amphipathic (BOTH). The results for GRID probe analysis is set out in Supplemental Table 1 and 2. 


\section{Results \& Discussion}

The binding interactions of the ginger compounds were investigated using the recently solved crystal structure of the murine 5-HT3 receptor (PDB entry: 4pir). Two subunits, representing the principle and complementary subunits $(\mathrm{A}+\mathrm{A}-)$, were extracted from the homomeric 5- $\mathrm{HT}_{3 \mathrm{~A}}$ pentamer for analysis since both the serotonin and allosteric binding sites are located at or near this interface (Figure 4A). 


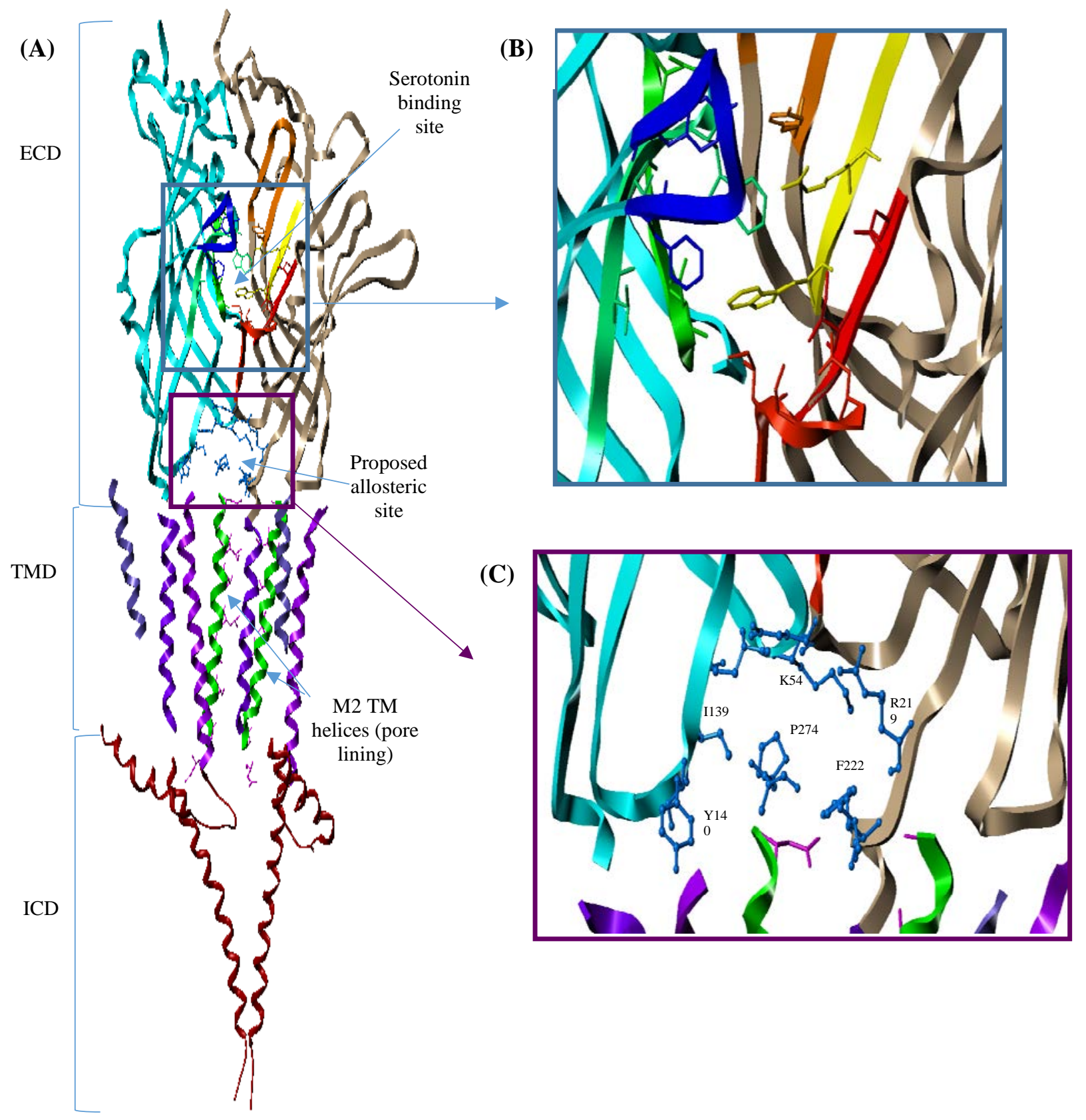

Figure 4. (A) Principle and complementary subunits of 5HT-3 $\mathrm{A}$ receptor, cyan and beige ribbons respectively. ECD containing orthosteric binding site and allosteric site at interface with TMD; TMD containing M1-M4 TM helices, M2 (green) containing pore-facing residues ion (magenta); (B) Orthosteric binding site. (C) Proposed allosteric site: Potential key residues for binding noncompetitive antagonists (blue, ball \& stick). 
The serotonin binding site is at the interface between two adjacent subunits (Figure 4B). Key residues within the principle subunit, A+, include N97, N101 (Loop A) in green; T52, T54, W156 (Loop B) in greenblue; F199, Y207 (Loop C) in blue. Residues suggested to be important for stabilising serotonin in the complementary subunit, A- include W63, R65, Y68 (Loop D) in yellow; Y124 (Loop E) in orange; D177, S179, V180 (Loop F) in red-orange; D42, D44 (Loop G) in red.[5, 39] Two allosteric binding sites have been proposed: one situated at the interface between the transmembrane region and the extracellular domain; the other proposed to reside within the membrane.[40] The location of the former site was delineated from site-directed mutagenesis studies by Trattnig et al.[40] and Chang.[6] Steroids and other modulators with a more non-polar nature would be preferred at the latter site. The former site was selected as most appropriate for the ginger compounds given their physical characteristics (Figure 4C).

A total of twenty-five ligands were incorporated into the docking experiments including serotonin (5-HT), 6,8 and 10-gingerol ([6G], [8G], [10G]) and 6,8 and 10-shogaol ([6S], [8S], [10S]), 6,8 and 10-dehydrogingerol ([6DHSG], [8DHSG], [10DHSG]). In addition, a number of positive and negative controls at the two sites were included. Positive controls, such as the 'setron' family of competitive antagonists, were selected based on known competitive antagonism. VUF10166, was selected as an example of an inhibitor able to discriminate between AB subunits of the 5- $\mathrm{HT}_{3}$ receptor.[41] A negative allosteric modulator (NAM), PU02, was included since it has been demonstrated to bind to a site which maps to an allosteric site found in other CYS-loop receptors. PU02 also appears to exhibit a biphasic NAM/positive allosteric modulator (PAM) upon mutation of certain residues in the region of this binding site.[40] Trattnig et al.[40] described the delicate relationship between gating and residues around this region. In addition, three known noncompetitive antagonists, including picrotoxin, likely to bind at an allosteric or alternate site were 
included. Varenicline was included as an example of a non-specific nAchR agonist with efficacy at the human 5-HT receptor.[42] We also incorporated structural analogs of the gingerols (capsaicin and curcumin) as well as decoy molecules, smaller neurotransmitters such as acetylcholine and GABA, known not to bind the 5-HT3 receptor.

A GRID analysis was performed to identify sites of strong binding interaction between the receptor and a range of small probes simulating various functional groups of the ligands (see Supplemental Table 1 and 2). Ligands were subsequently docked into the two sites to compare binding interactions at each site. Grid contours have been superimposed over the docked poses where appropriate.

Table 1: Surflex-Dock results for Serotonin and Allosteric Sites

\begin{tabular}{|c|c|c|c|c|c|c|c|c|c|}
\hline & & \multicolumn{4}{|c|}{ Serotonin Site } & \multicolumn{4}{|c|}{ Allosteric Site } \\
\hline Compound & IC50 & $\begin{array}{c}\text { Total } \\
\text { score } \\
(- \\
\left.\log K_{d}\right)\end{array}$ & Cscore & Hbonds ${ }^{\mathrm{b}}$ & $\begin{array}{l}\text { Interacting } \\
\text { Residues }^{c}\end{array}$ & $\begin{array}{c}\text { Total } \\
\text { score } \\
(- \\
\left.\log _{d}\right)\end{array}$ & Cscore & Hbonds ${ }^{b}$ & $\begin{array}{l}\text { Interacting } \\
\text { Residues }^{\mathrm{c}}\end{array}$ \\
\hline \multicolumn{10}{|c|}{ Ginger Compounds } \\
\hline 6G & $\begin{array}{c}30 u \mathrm{M} \\
(\mathrm{rat})^{\mathrm{i}}\end{array}$ & 8.7 & 1 & 3 & E209 R65 & 8.26 & 1 & 4 & $\begin{array}{l}\text { E219 Q56 } \\
\text { F222 E53 }\end{array}$ \\
\hline 8G & $\underset{\text { range }}{u \mathrm{Mi}}$ & 10.25 & 5 & 4 & $\begin{array}{c}\text { T154 E209 } \\
\text { R65 }\end{array}$ & 8.84 & 5 & 3 & $\begin{array}{c}\text { E53 R219 } \\
\text { F222 }\end{array}$ \\
\hline 10G & $\underset{\text { range }}{u \mathrm{M}^{\mathrm{ii}}}$ & 10.81 & 4 & 5 & $\begin{array}{l}\text { T154 E209 } \\
\text { K211 T152 }\end{array}$ & 8.26 & 1 & 5 & $\begin{array}{c}\text { T280 I139 } \\
\text { E53 Q56 }\end{array}$ \\
\hline 6S & $\begin{array}{c}9,3 u \mathrm{M} \\
{\text { (rat })^{\mathrm{i}}}\end{array}$ & 8.31 & 0 & 2 & $\begin{array}{l}\text { N101 } \\
\text { W156 }\end{array}$ & 6.52 & 0 & 3 & $\begin{array}{c}\text { E53 F222 } \\
\text { Q56 }\end{array}$ \\
\hline $8 \mathrm{~S}$ & $\begin{array}{c}u \mathrm{M} \\
\text { range }^{\mathrm{ii}}\end{array}$ & 9.06 & 5 & 4 & $\begin{array}{c}\text { R65 S155 } \\
\text { T154 }\end{array}$ & 7.19 & 2 & 2 & K54 F222 \\
\hline $10 S$ & $\begin{array}{c}u \mathrm{M} \\
{\text { rang } \mathrm{e}^{\mathrm{ii}}}\end{array}$ & 9.34 & 2 & 2 & T152 N101 & 8.29 & 5 & 1 & F222 \\
\hline
\end{tabular}




\begin{tabular}{|c|c|c|c|c|c|c|c|c|c|}
\hline 6DHSG & - & 6.97 & 0 & 3 & $\begin{array}{c}\text { T152 N101 } \\
\text { K211 }\end{array}$ & 6.28 & 0 & 3 & $\begin{array}{c}\text { E53 Q56 } \\
\text { K54 }\end{array}$ \\
\hline 8DHSG & - & 8.56 & 0 & 3 & $\begin{array}{c}\text { L157 N101 } \\
\text { Y207 }\end{array}$ & 6.61 & 0 & 1 & E186 \\
\hline 10DHSG & - & 9.07 & 2 & 2 & L157 N101 & 6.85 & 4 & 3 & $\begin{array}{c}\text { E53 Q56 } \\
\text { K54 }\end{array}$ \\
\hline \multicolumn{10}{|c|}{ Endogenous Ligand } \\
\hline serotonin & $7.8 \mathrm{uM}^{\mathrm{a}, \mathrm{i}}$ & 5.63 & 4 & 5 & $\begin{array}{l}\text { E173 S176 } \\
\text { D42 D177 }\end{array}$ & 6.02 & 0 & 4 & $\begin{array}{c}\text { Q184 E53 } \\
\text { D138 L137 }\end{array}$ \\
\hline \multicolumn{10}{|c|}{ Competitive Antagonists } \\
\hline Ondansetron & $\begin{array}{l}4.9 \mathrm{nM} \\
\text { (human) }\end{array}$ & 5.22 & 5 & 1 & T154 & 4.85 & 0 & 1 & Q56 \\
\hline Granisetron & $\begin{array}{l}1.4 \mathrm{nM} \\
\text { (human) }\end{array}$ & 5.51 & 5 & 1 & E209 & 4.87 & 0 & 0 & - \\
\hline Palonosetron & $\begin{array}{c}31.6 \mathrm{nM} \\
\text { (rat) }\end{array}$ & 5.74 & 0 & 1 & R65 & 5.1 & 0 & 0 & - \\
\hline Dolasetron & $\begin{array}{c}20.03 \\
\text { nM } \\
\text { (NG108- } \\
15)\end{array}$ & 6.9 & 0 & 3 & R65 T154 & 5.43 & 1 & 0 & - \\
\hline Ramosetron & $\begin{array}{c}11-12 \\
\text { nM } \\
\text { (human) }\end{array}$ & 6.48 & 4 & 1 & T154 & 5.65 & 2 & 2 & P274 Q56 \\
\hline VUF10166[41] & $\begin{array}{l}\text { 40nM } \\
\text { (AB } \\
\text { subunit } \\
\text { only) }\end{array}$ & 5.13 & 5 & 1 & R65 & 5.8 & 4 & 0 & - \\
\hline \multicolumn{10}{|c|}{ Agonist (non-specific) } \\
\hline Varenicline[43] & $\begin{array}{c}5.9 \\
\mathrm{uM}[42] \\
\left(\mathrm{EC}_{50}\right)\end{array}$ & 5.09 & 4 & 2 & R65 N101 & 4.23 & 3 & 1 & P274 \\
\hline \multicolumn{10}{|c|}{ Structural Analogues of ginger actives } \\
\hline Capsaicin & - & 8.54 & 0 & 4 & R65 N101 & 9.23 & 1 & 3 & $\begin{array}{c}\text { K54 R219 } \\
\text { F222 }\end{array}$ \\
\hline Curcumin & - & 8.77 & 0 & 9 & $\begin{array}{c}\text { R65 T154 } \\
\text { S155 D177 } \\
\text { S179 }\end{array}$ & 7.02 & 0 & 3 & $\begin{array}{c}\text { R219 E53 } \\
\text { E186 }\end{array}$ \\
\hline \multicolumn{10}{|c|}{ Non-Competitive Ligands } \\
\hline
\end{tabular}




\begin{tabular}{|c|c|c|c|c|c|c|c|c|c|}
\hline PU02 & $\begin{array}{l}1.3 \mathrm{uM} \\
\text { (human) }\end{array}$ & 5.8 & 5 & 3 & D177 S179 & 4.33 & 2 & 1 & D138 \\
\hline Bicuculline & $\begin{array}{c}191 \\
u \mathrm{M}[44]\end{array}$ & 7.09 & 5 & 1 & R65 & 6.01 & 1 & 3 & - \\
\hline Picrotoxin & $\begin{array}{c}440 \\
u \mathrm{M}[44]\end{array}$ & 4.77 & 5 & 4 & $\begin{array}{l}\text { E102 S150 } \\
\text { S136 N148 }\end{array}$ & 4.96 & 0 & 4 & $\begin{array}{c}\text { Y46 N183 } \\
\text { S136 }\end{array}$ \\
\hline Ginkgolide & $\begin{array}{c}727 \\
u \mathrm{M}[44]\end{array}$ & 4.25 & 2 & 7 & $\begin{array}{c}\text { K211 S150 } \\
\text { E102 T152 } \\
\text { N101 }\end{array}$ & 3.94 & 3 & 3 & $\begin{array}{c}\text { T280 D138 } \\
\text { I139 }\end{array}$ \\
\hline \multicolumn{10}{|l|}{ Decoys } \\
\hline Acetylcholine & - & 4.9 & 0 & 0 & & 4.95 & 3 & 1 & - \\
\hline GABA & - & 4.9 & 4 & 3 & W156 R65 & 4.76 & 1 & 3 & - \\
\hline
\end{tabular}

IC50 data from BindingDB (http://www.bindingdb.org/bind/) unless otherwise referenced; ${ }^{\mathrm{i} J i n}$ et al 2014; ${ }^{\mathrm{ii}}$


ligand; c target residues hydrogen bonding to ligand. Residues previously identified as important for binding serotonin (blue). Highest scoring ligand in each site (red).

The docking results are presented in Table 1. Experimental inhibition assay data is included where available as well as the key residues with which hydrogen bonds were observed to contribute to the binding affinity for each ligand. For the serotonin site, total scores ranged from 4.25 to 10.81 $\mathrm{kcal} / \mathrm{mol}$, with the ginger compounds' scores ranging from 6.97 and $10.81 \mathrm{kcal} / \mathrm{mol}$. The setron family of compounds clustered around midfield while the structural analogs scored similarly to the ginger compounds. Serotonin itself scored in the range of the setron compounds. The decoys bound with the lowest affinities (less than $5.00 \mathrm{kcal} / \mathrm{mol}$ ) along with picrotoxin and gingkolide although bicurculline scored $7.09 \mathrm{kcal} / \mathrm{mol}$. At the allosteric site, the total scores ranged from 3.94 to $9.23 \mathrm{kcal} / \mathrm{mol}$ with capsaicin scoring highest. The ginger compounds also scored among the highest at this site ranging from 6.28 to $8.84 \mathrm{kcal} / \mathrm{mol}(\mathbf{8 G})$. The remainder of the compounds followed a similar total score trend as for the serotonin site. 
Comparison of the cscores for the ginger compounds at both sites reveals a relatively high degree of similarity. The only cases where there was significant difference was for 10G at the serotonin site scoring 4 compared to a 1 at the allosteric site. A cluster analysis of the 20 highest scoring poses for each ligand at each site was performed. The results for $\mathbf{1 0 G}$ showed much less variation in occupied 3D space for the 20 docked poses at the serotonin site which appears to correlate with the higher cscore value. This is more likely to be due to a preference for a particular conformation than steric constraints given the conformation space available to them.

This trend was repeated with the structural analogs inferring that this structural family of compounds binds more favorably at the allosteric site. In contrast, there was a higher consensus for serotonin and the setron antagonists at the serotonin binding site. Consensus was high at both sites for the decoys, consistently performing poorly in their total scores.

\section{Serotonin Binding Site Results}

Of the ginger compounds, gingerols had the highest total score. A contributing factor towards the high score is likely to be the advantage taken of hydrogen bonding opportunities within the site. Both the shogaols and dehydroshogaols lack an alkyl hydroxyl group and have less flexibility due to the double bond. Due to their flexibility the length of their carbon chains did not negatively impact on their total scores. Non-competitive ligands and decoys, acetylcholine and GABA had the lowest score measured.

The serotonin site has a high degree of hydrophobic character and our results are in agreement with this description. Figure 6 shows the predicted sites of strong interaction with a hydrophobic probe. A contour level of $-1.5 \mathrm{kcal} / \mathrm{mol}$ is indicative of a lipophilic region. Serotonin is observed to dock into a more polar region than the setron compounds which is as expected given their greater 
degree of lipophilicity. A strong site of interaction correlates well with the position of the aromatic ring and alkyl chain of docked [6]-gingerol).

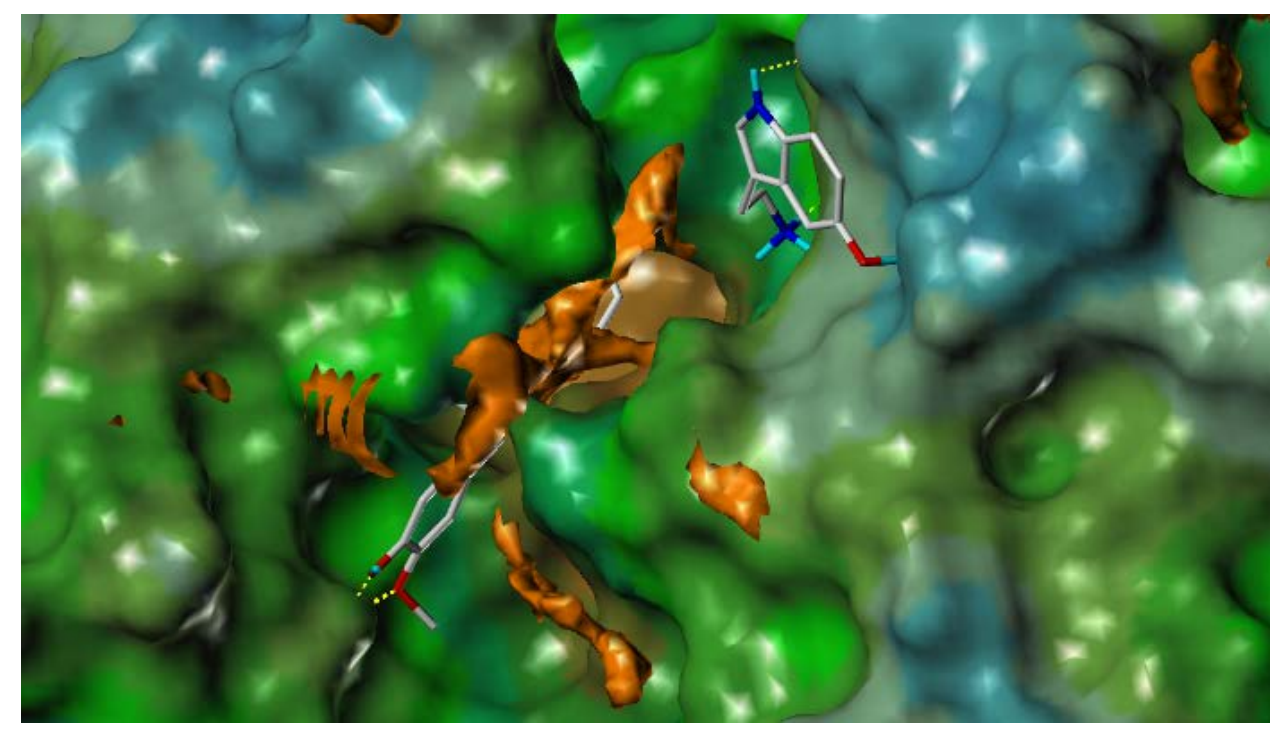

Figure 6. 5-HT and 10G docked into serotonin site. Hydrophobic probe (orange contours). Note the site where $5 \mathrm{HT}_{3}$ is bound is more polar than the site occupied by $\mathbf{1 0 G}$.

The majority of ligands, including the ginger compounds, occupied a site more interior and hydrophobic than that bound by serotonin (Figure -B and C). Despite the 3 apparent hydrogen bonds with D177 and one each between S179 and W165, the total score for serotonin was lower than all ginger compounds, structural analogs, granisetron, dolasetron and romasetron.

The serotonin site is lined with a number of aromatic residues, termed the 'aromatic box' and provides stability to the site.

Figure 8A shows the three particularly strong sites of interaction with a hydrophobic probe. and correlate well with the docked positions of hydrophobic moieties of the ligands such as the alkyl tails of the ginger compounds and the aromatic ring systems of other compounds. Contours for a 
cationic amine probe showed excellent correlation to the site of the docked ammonium group of serotonin (Figure 8B). 
(A)

(C)
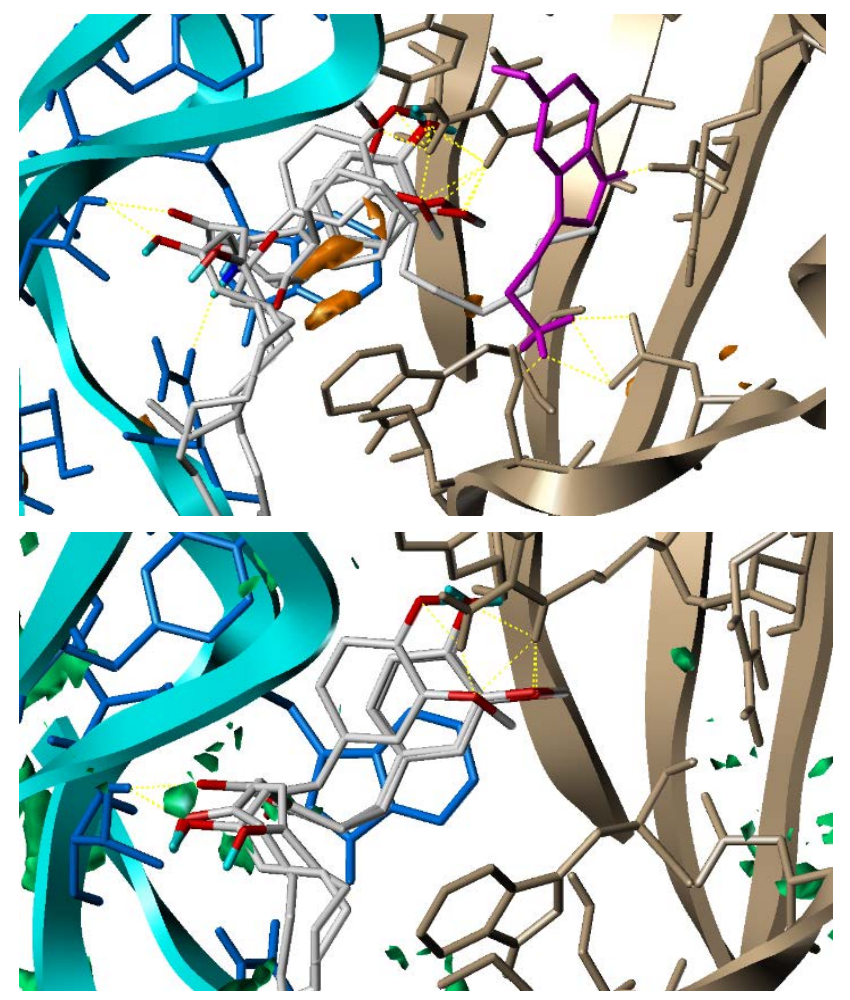

(E)

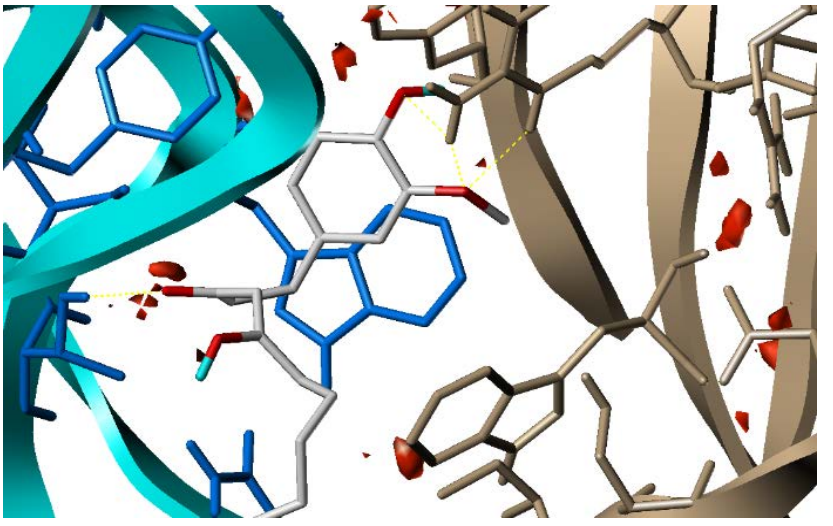

(B)

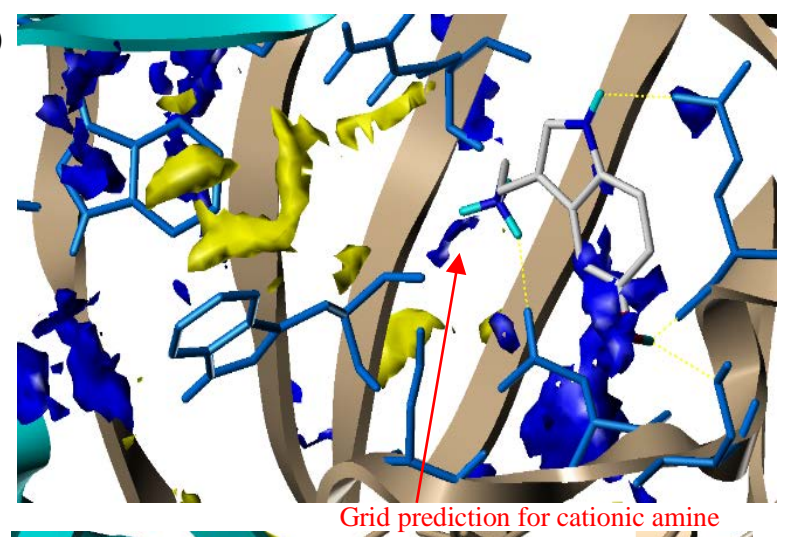

(D)'

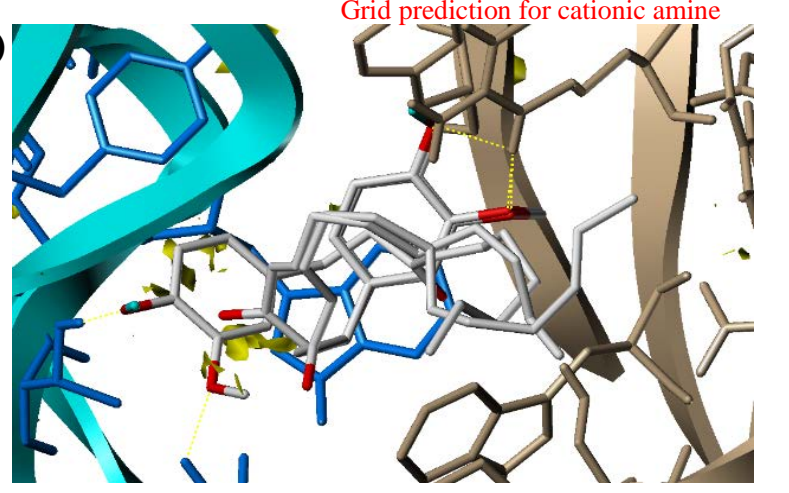

(F)

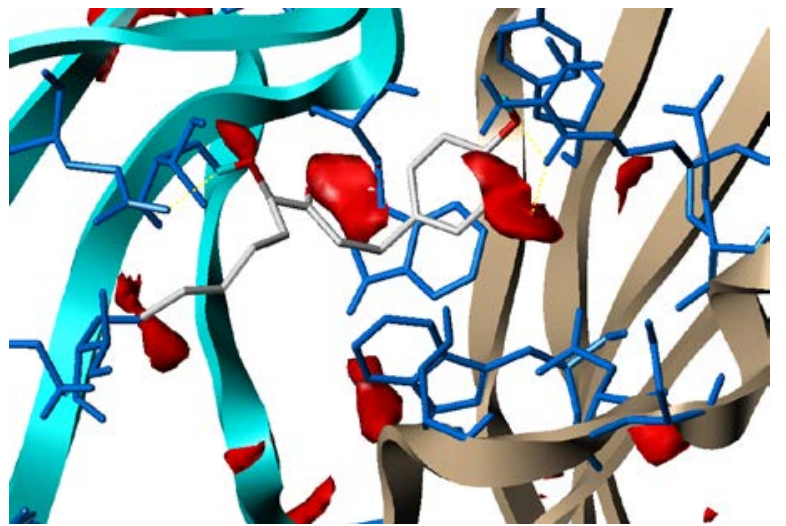

Figure 8. Serotonin binding site (A) Docked ginger compounds (atom types) and I (magenta).

Hydrophobic probe contoured at $-1.5 \mathrm{kcal} / \mathrm{mol}$. (B) I with contours for hydrophobic probe (yellow,

$-1 \mathrm{kcal} / \mathrm{mol}$ ) and amine probe (blue, $-15 \mathrm{kcal} . \mathrm{mol}$ ) (C) Docked poses of $\mathbf{6 , 8}$ and $\mathbf{1 0 G}$ with alkyl hydroxyl probe contours (green-blue, 10.5kcal/mol) (D) Docked poses of 6,8 and $10 \mathrm{~S}$ with phenyl hydroxyl probe contours (-10.5 kcal/mol, yellow) (E) Docked poses of 10G with carbonyl oxygen probe contours (-7 kcal/mol, red-orange) (F) Docked 6G with contours for aromatic probe (red, -

\section{$3.5 \mathrm{kcal} / \mathrm{mol})$}

The gingerols compounds are distinguished from the other more oxidized ginger compounds by 
the presence of an alkyl hydroxyl group. Sites of polar interactions with an alkyl hydroxyl group correlates well with the position of alkyl hydroxyl probe of 6G (Figure 8C). Similarly, the docked positions of a carbonyl oxygen and aromatic rings correlated well with the sites predicted by GRID (Figure 8E and 8F). Sites of binding interactions predicted by GRID between a phenyl hydroxyl probe was less well correlated with the docked position of the same group in 6G (Figure 8D). There are a number of valid reasons why the results from GRID would not always be expected to overlap with similar moiety positions in docked poses. Apart from different algorithms for determining interactions, docking algorithms deal with entire molecules rather than simply small moieties and thus are more spatially restricted. Nevertheless, it is of interest to view the site in pure terms of particular functional group interactions.

(A)

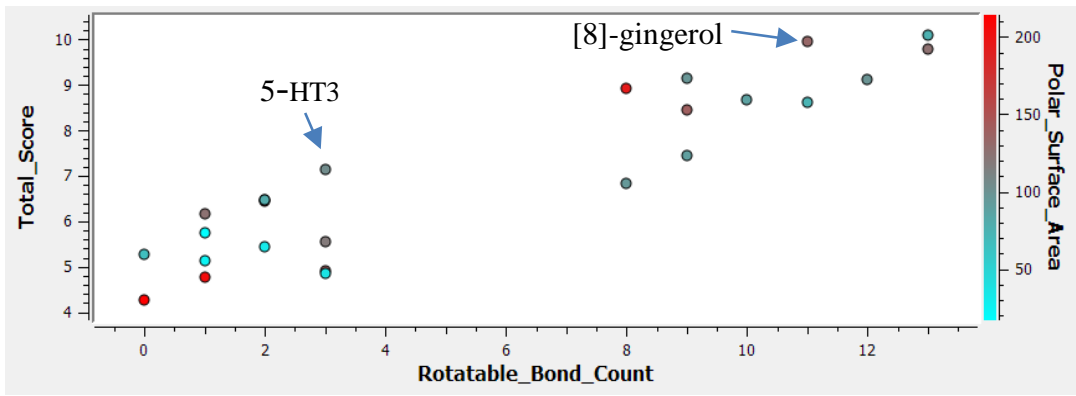

(B)

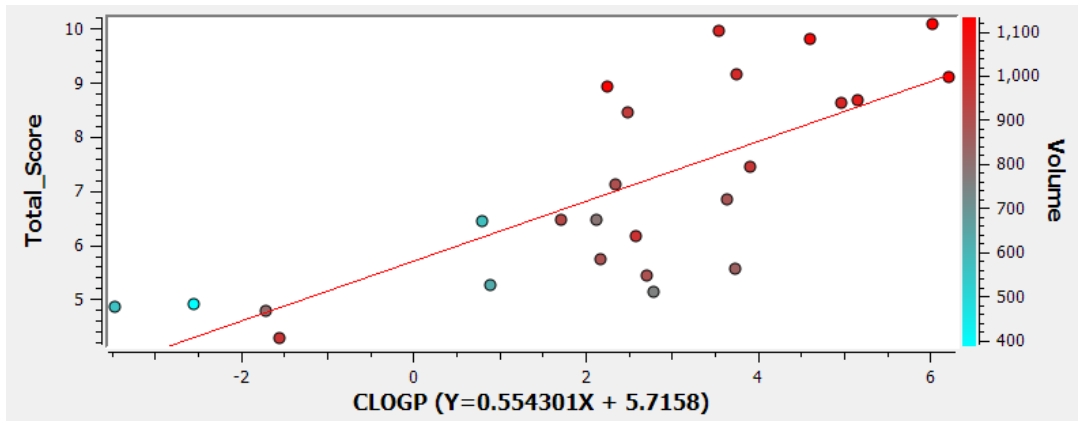

Figure 9. (A) Ligand rotatable bonds compared to total score and polar surface area. (B) Ligand clogP values versus total score and coloured by volume. 
Unexpectedly, the ginger compounds scored highest in the serotonin binding site. In terms of drug-like characteristics, the ginger compounds have a high non-covalent interaction potential meaning that they possess a range of structural moieties required for maximizing binding affinity. These include an aromatic ring (pi stacking), alkyl tail (hydrophobic and Van der Waal interactions), hydrogen bond donors (phenol and hydroxyl) and acceptors (carbonyl and hydroxyl oxygens) for maximizing hydrogen bonding interactions. The ginger compounds have a high degree of flexibility as illustrated by the observed correlation between rotatable bonds and total score (Figure 9). The same features are similarly found in the structural analogs, capsaicin and curcumin which also scored highly in the serotonin binding site. In addition to flexibility, there is a clear correlation between hydrophobic character and total score with all the top scoring ginger compounds and structural analogs having high, positive clogP values. Volume is similarly positively correlated with total scores.

Current molecular docking algorithms are limited in their capacity to accurately model all factors present in vivo. Target flexibility, explicit solvent and some types of non-covalent interactions, for example, are often not considered or dealt with poorly. As a result, caution in the interpretation of these results is required. Interactions between both competitive and non-competitive antagonists with the receptor have been described by Thompson et al.[39] to undergo a pathway as they progress from bound to unbound which may involve several transient sites. Furthermore, the nicotinic receptor, AChBP, also of the CYS loop receptor is known to undergo substantial quaternary twisting of the subunit interface upon activation of the ion channel and bending of the extracellular domain.[45] It is feasible then to consider similar conformational movements of the 5- $\mathrm{HT}_{3}$ receptor and concomitant changes to binding sites. In this light, it is not surprising that we 
see the ginger compounds binding well to this site. The crystal structure was assumed to have adopted a closed conformation upon binding of the inhibitory VHH nanobody. It is possible that serotonin may have scored higher had the receptor been in a more open channel conformation and ligand ranking likely to be quite different.

Binding studies reveal a complexity in mechanisms of action with respect to how particular ligands may interact with different subunit stoichiometry. The potent inhibitor, VUF10166 for example, was found to displace granisetron at the orthosteric binding site in an A+A-binding site but acted at an alternate site at an A+B- binding.[46] The 5-HT3A crystal structure used in this study was homomeric (A+A-).

Prior to the determination of the mouse crystal structure, site directed mutagenesis studies revealed a number of residues important for activation of the $5-\mathrm{HT}_{3}$ receptor or binding of serotonin.[47] These included Y46, F103, S136 and D138 (mouse numbering). These dues are more posterior to the serotonin site shown in the mouse structure and were not seen to interact with any of the ligands. In the crystal structure, however, Hassaine et al.[5] further identified several key residues in the crystal structure as important for serotonin binding. For example, we found that R65 played a key role in binding ligands at the serotonin site and supports experimental observations. Several ginger compounds, structural analogs and competitive antagonists interacted with this residue through hydrogen bonding. In addition, N101 and T154 were also important for stabilizing ligands via hydrogen bonding. Serotonin was found to interact with D42 and D177 as well as S179. These residues were implicated by Hassaine et al.[5] as forming the serotonin binding site. The residues forming the most hydrogen bond interactions with the ligand database were R65, N101 and T154. Ginger ligands formed hydrogen bonds with several residues, predominantly R65, T154 and N101. We found previously unidentified residue, E102, contributed to stabilization of 
[10]-dehydroshogaol. The setron group of ligands docked into two main regions within the site. Ondasetron and dolasetron bound closer to the complementary site where 5-HT3 was found to interact while granisetron and romasetron bound closer to the primary subunit face. Palonasetron was docked in between these regions (Figure 10A).
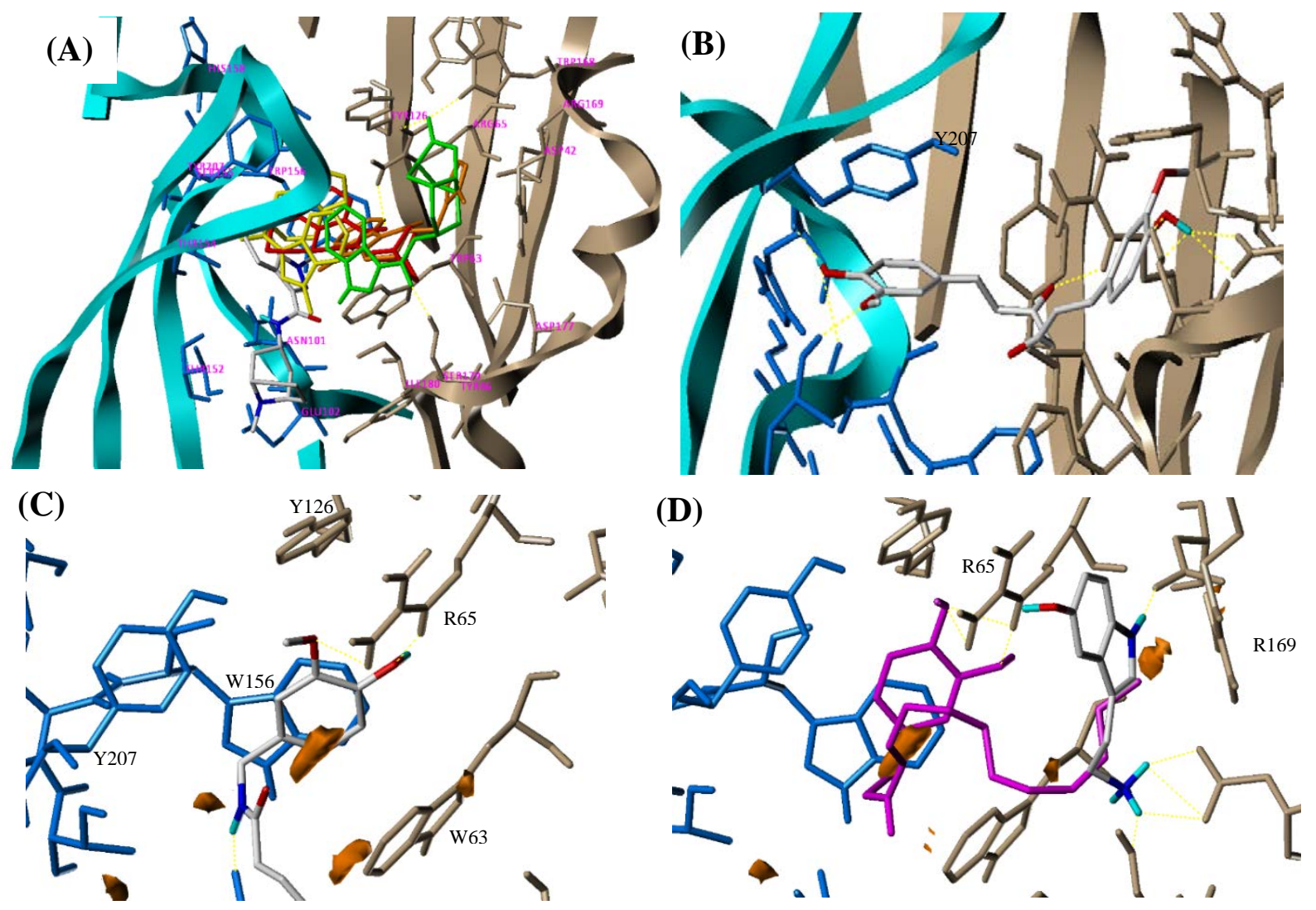

Figure 10. (A) Granisetron (atom colours) ondasetron (orange) dolasetron (green) romasetron (yellow) palonosetron (red). (B) Curcumin (atom colours) docked into serotonin site. Additional stability by possible pi stacking interaction with Y207. (C) Capsaicin docked into serotonin site depicting the aromatic box created by Y207, W156 (primary subunit, blue) and Y126 \& W63 (complementary subunit, beige). (D) Serotonin (atom colours) and 10G (magenta). Hydrophobic probe contoured at $-1.5 \mathrm{kcal} / \mathrm{mol}$ for $\mathrm{C}$ and $\mathrm{D}$.

Possible pi stacking interactions between Y207 were identified which may confer stability to the docked ligands with 10G and other ligands such as curcumin (Figure 10B). Other competitive 
antagonists interacted predominantly with R65 and T154; both of which also interacted with gingerols.

Our docking results are in agreement with these residues as important for hydrogen bonding with the site. Figure 10-C clearly depicts the aromatic box of the serotonin site created by the residues Y126, and W63 of the complementary subunit and Y207 and W156 of the primary subunit. The high scoring ginger compounds and their structural analogs were observed to dock in a similar orientation with their aromatic ring embedded in this box permitting hydrogen bonding with the side chain cationic amine of R65. In contrast, serotonin's aromatic ring appears to take advantage of a cation-pi interaction with R65 (Figure-10D). This interaction was proposed by Hassaine et al[5] with granisetron. We further suggest that a second cation-pi interaction on the opposite face of serotonin's aromatic ring is possible with R169.

\section{Allosteric Binding Site Analysis}

Allosteric modulation facilitates fine tuning of ion permeation through the channel by signal dampening, for example, depending on the stoichiometry of the subunits and the number of serotonin ligands able to bind one receptor. Multiple modes of regulation have been noted in other CYS-loop receptors and are similarly likely in the serotonin receptor and involve a number of allosteric binding sites. Endogenous membrane lipids have been suggested to modulate ion permeation by binding to specific regions of the transmembrane channel. Exactly where noncompetitive antagonists of the 5- $\mathrm{HT}_{3}$ receptor may bind is yet to be fully elucidated.

The transmembrane domain of the CYS-loop receptors are functionally similar with key regions along the length of the ion permeation pathway being designated with a prime notation such that the pre-M2 region, identified as -20' contains a ring of cationic residues.[46] Certain residues of 
the M2 helix face in toward the channel (Figure 11) and site-directed mutagenesis studies have identified a number to important for channel function.

Furthermore, non-competitive antagonists (NCAs) such as picrotoxin can differentiate different subunit compositions in the receptor.[48] The most likely position for many of the exogenous NCAs is the intersubunit interface at the top of the transmembrane domain. Another allosteric site is proposed in the pre-M2, ECM intersubunit interface. Anesthetics and small alcohols have been shown to interact at a similar site in GABA and glycine receptors.[49, 50] These compounds illicit similar effects on the 5-HT3 receptor.[11] Since the structure of one such anesthetic, lidocaine, had a degree of structural similarity to serotonin and the ginger compounds, our study focused on the latter allosteric site.

\section{(A)}

Outer ECM region
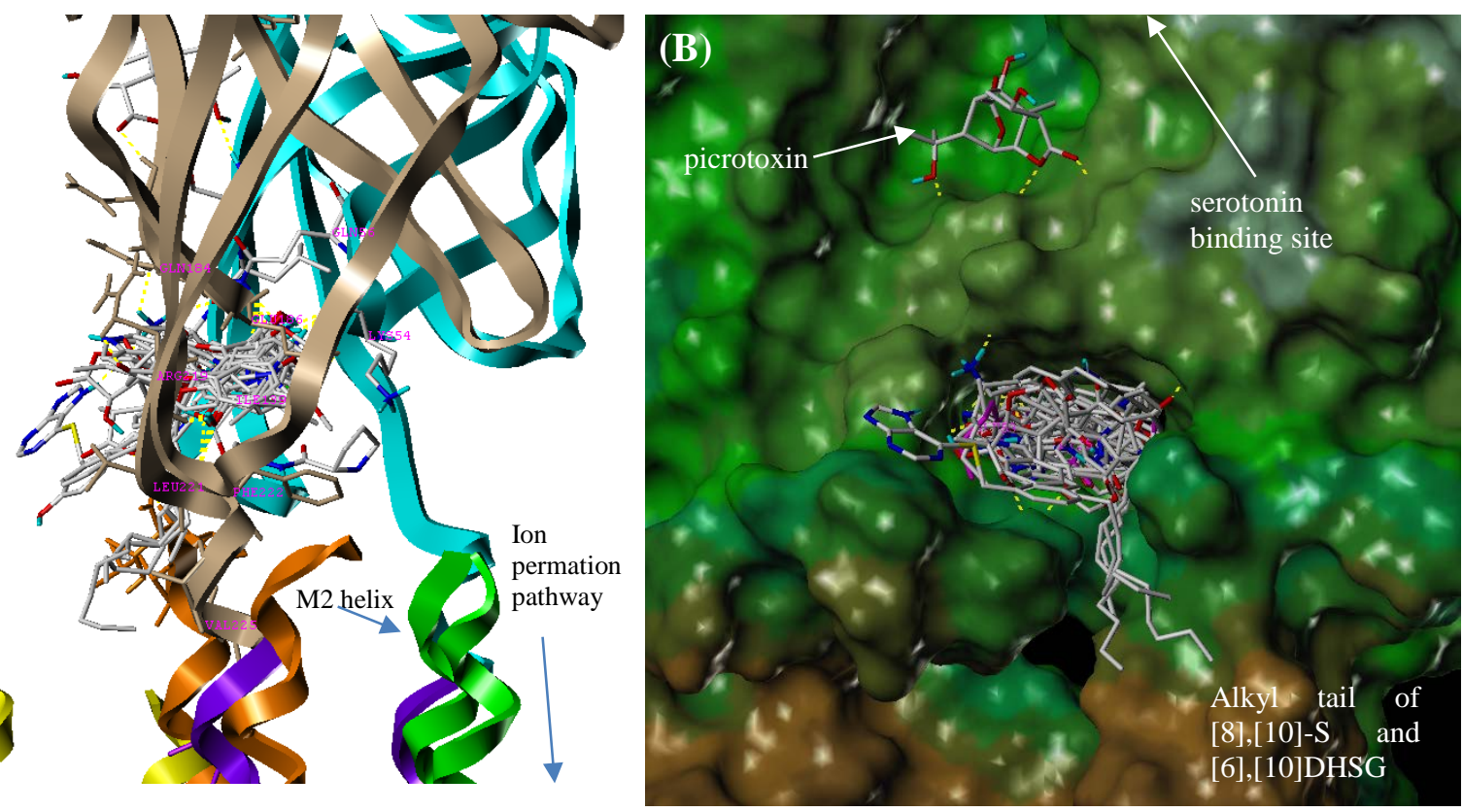

Figure 11. (A) Docked ligands within the allosteric binding site at the ECM/TM interface between primary and complementary subunits. Side view with M2 TM helix (green) (B) Superimposition of docked ligands at the allosteric site. 8G (magenta). Docked picrotoxin indicated position closer towards serotonin binding site. Alkyl tails of 8,10S and 6,10DHSG. 
The orientation of the docked ligands within the allosteric binding site is depicted in Figure 10A with contoured surface coloured according to lipophilic character (Figure 11B). Note that picrotoxin is bound to a unique site midway between the serotonin and allosteric sites. This ligand may bind to a different allosteric site with the $\mathrm{A}+\mathrm{B}$ - subunit interface. The allosteric binding site depicted occupies a greater volume than that of the serotonin binding site, enabling some ginger compounds to adopt a more extended conformation. This appears to facilitate a favourable hydrophobic interaction between the alkyl moiety of these ligands with the hydrophobic region found closer to the transmembrane domain.
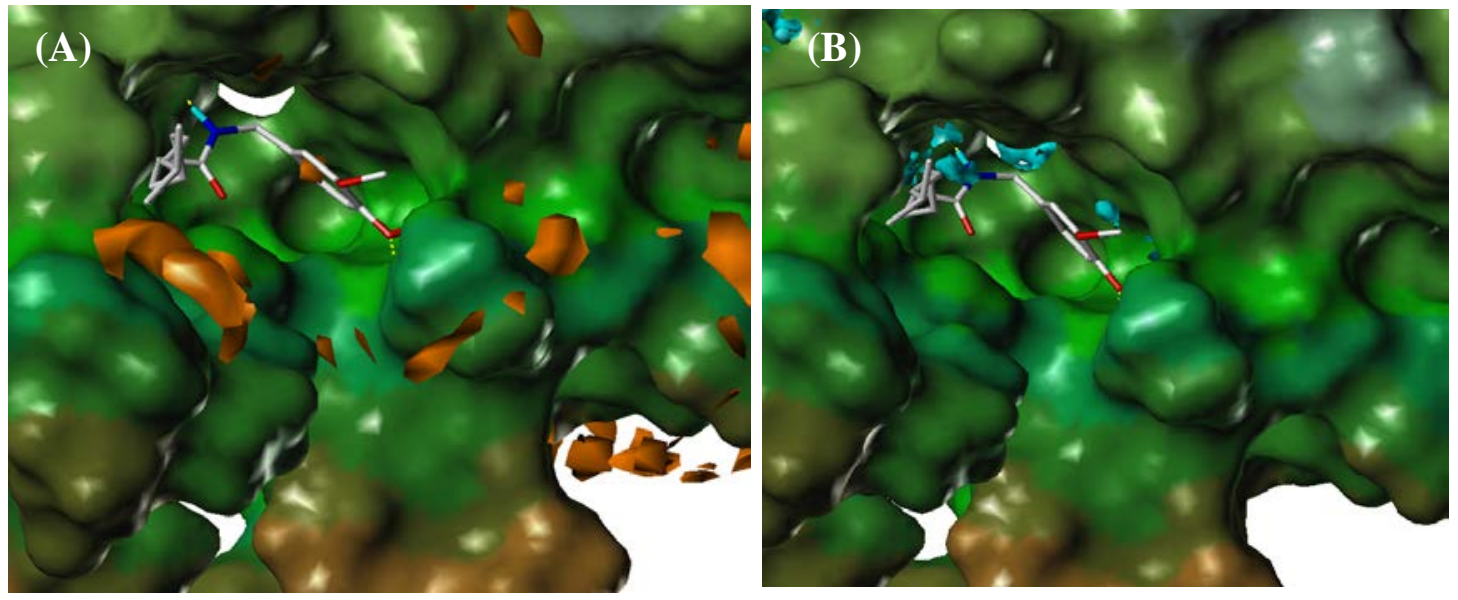

Figure 11. Top scoring ligand, capsaicin at allosteric site. (A): GRID contours for a hydrophobic probe (-0.5kcal/mol). (B): GRID contours for a water probe (-11 kcal/mol). Connolly surface coloured by lipophilic character.

The ginger compounds and structural analogs also scored highest in this binding site with capsaicin attaining the highest total score. As demonstrated by the lower level of contouring for the hydrophobic probe, the allosteric site is more polar than the serotonin cavity although there are particular regions with hydrophobic character which correlate well with hydrophobic moieties of the ligands (Figure 12A). Figure 12B shows sites of strong interaction with a water probe which correlate well with the docked positions of polar groups on the ligands. 
Comparison between the different ginger compounds showed that the gingerols generally scoring higher as a group (Figure 13) with all three adopting a similar orientation within the site. This trend is continued with the shogaols scoring generally higher than the dehydroshogaols. This trend correlates with the higher polarity of the gingerols compared to the other ginger compounds and, in this context, would therefore bind with higher affinity in a more polar site.

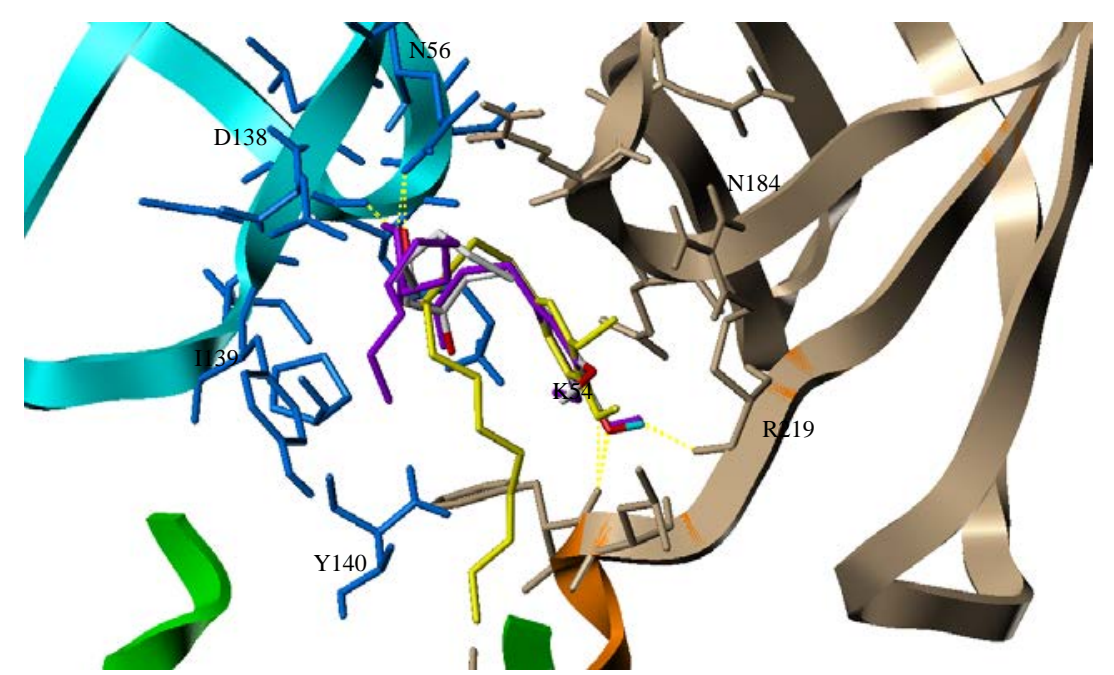

Figure 12. Superimposition of 6G (atom colours), 8G (yellow), 10G (violet) in allosteric site.

Serotonin and the competitive antagonists ranked moderately at this site with all setron ligands binding in a similar location to the gingerols (Figure 14A and B). PU02 occupied a unique site lower down toward the transmembrane region forming a pi stacking interaction with Y140. (Figure $14-\mathrm{C})$ 


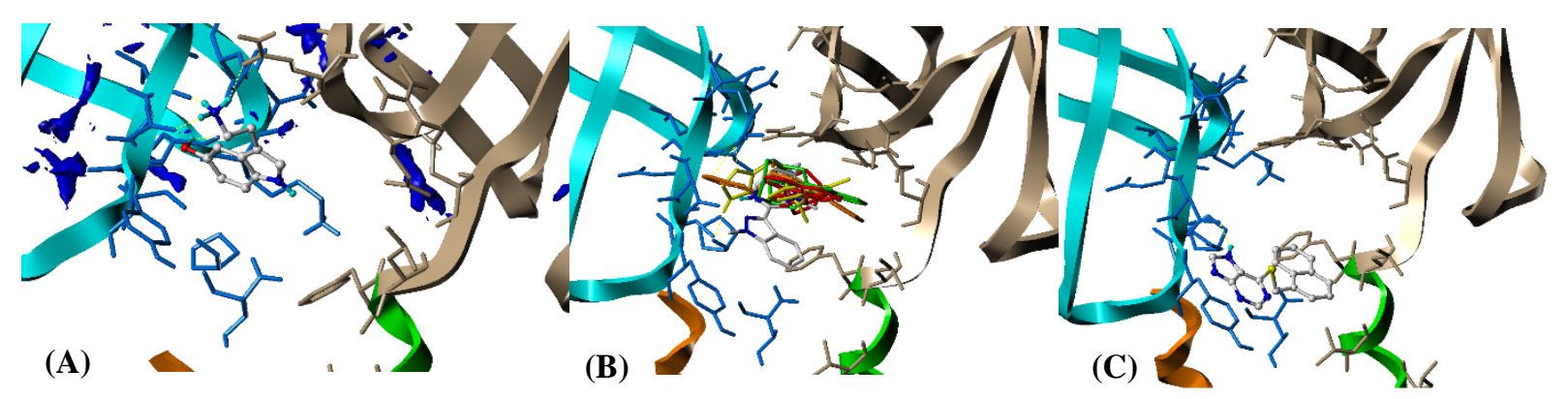

Figure 13. Allosteric site: (A) Serotonin docked into allosteric site with amine cation probe contoured at $-15 \mathrm{kcal} / \mathrm{mol}$ (B) Setrons (granisetron (atom colours), ondansetron (orange), dolasetron (green), romasetron (yellow) palonosetron (red ) (C) Potential pi stacking interaction between PU02 and Y56.

Our analysis identified R219, Q56, F222, E53, K54 and T280 as the key binding residues for this site with minor contributions from I139, P279 and E186. The key residues important for forming hydrogen bonds with the ginger compounds were I139, R219, Q56, F222, and Q53. F222, in particular, was involved with hydrogen bonding with all shogaols and most gingerols.

(A)

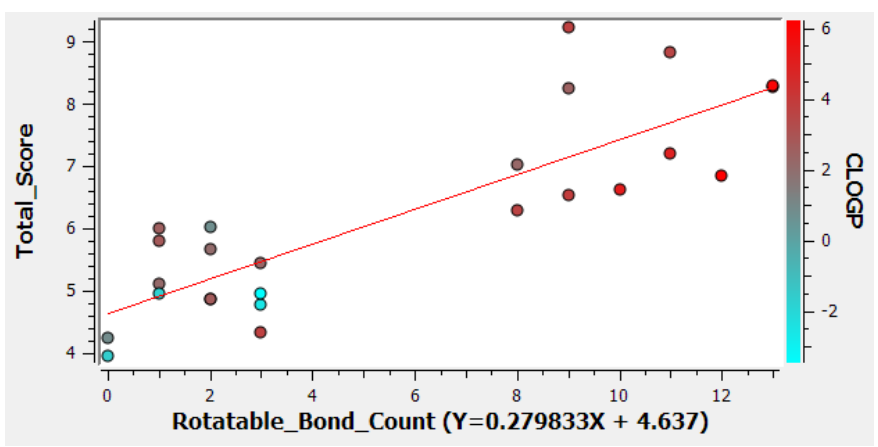

(B)

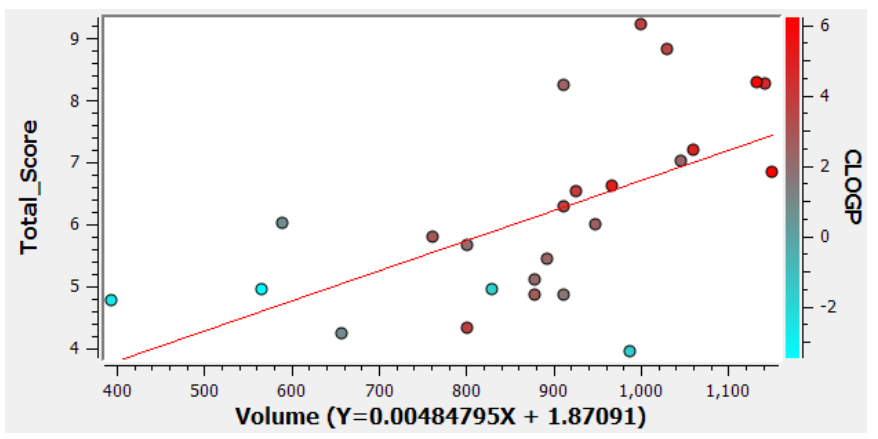

Figure 15. (A) Scatter plots of rotatble bonds Vs Total score with colour axis, clogP (B) Scatter plots of Volume Vs Total score with colour axis, clogP.

Compared to serotonin and the ginger compounds, other competitive antagonists exhibited relatively low levels of hydrogen bonding interactions within the allosteric site suggesting less available hydrogen bond donors/acceptors at this site compared to the serotonin site. Flexibility 
played a positive role in how well the ligands scored at this site as it did within the serotonin site (Figure 15-A). Volume and increasing hydrophobicity were observed to play a similar role in contributing to a higher total score. (Figure 15-B).

A sequence alignment (Figure 16) was performed of the mouse and human $5-\mathrm{HT}_{3} \mathrm{~A}$ and $\mathrm{B}$ receptors to map the key residues identified in the mouse structure with those in the human receptor subunits and determine if the newly identified residues were conserved. Human and mouse A subunits share $84.7 \%$ sequence identity. Human and mouse B subunits share $73.2 \%$ sequence identity. Human A and B subunits share $44.75 \%$ identity whereas mouse A and B share $42.4 \%$ identity. It was found that all key residues important for binding the ginger compounds (as well as serotonin) in the serotonin site were conserved between human and mouse A subunits. For clarity, mouse numbering is noted in red while human sequence numbering was in black. Hassaine et al.[5] noted the importance of R218 at the TM interface and we show here this residue to be conserved in both the human A and B subunits. Note that E102 identified in this analysis was found to be similarly conserved. For the allosteric site, all residues noted as important for binding the ginger compounds were conserved between mouse and human sequences. Given the high degree of sequence similarity between the mouse and human subunits and the conservation of those important receptors, it is unlikely that the species difference would account for the finding that the ginger compounds bound well in both sites.

A comparison of the present docking results to available biological $\mathrm{IC}_{50}$ data is presented in Table 2. Compounds were listed in order of potency at the human 5-HT3 receptor (where data was available). 


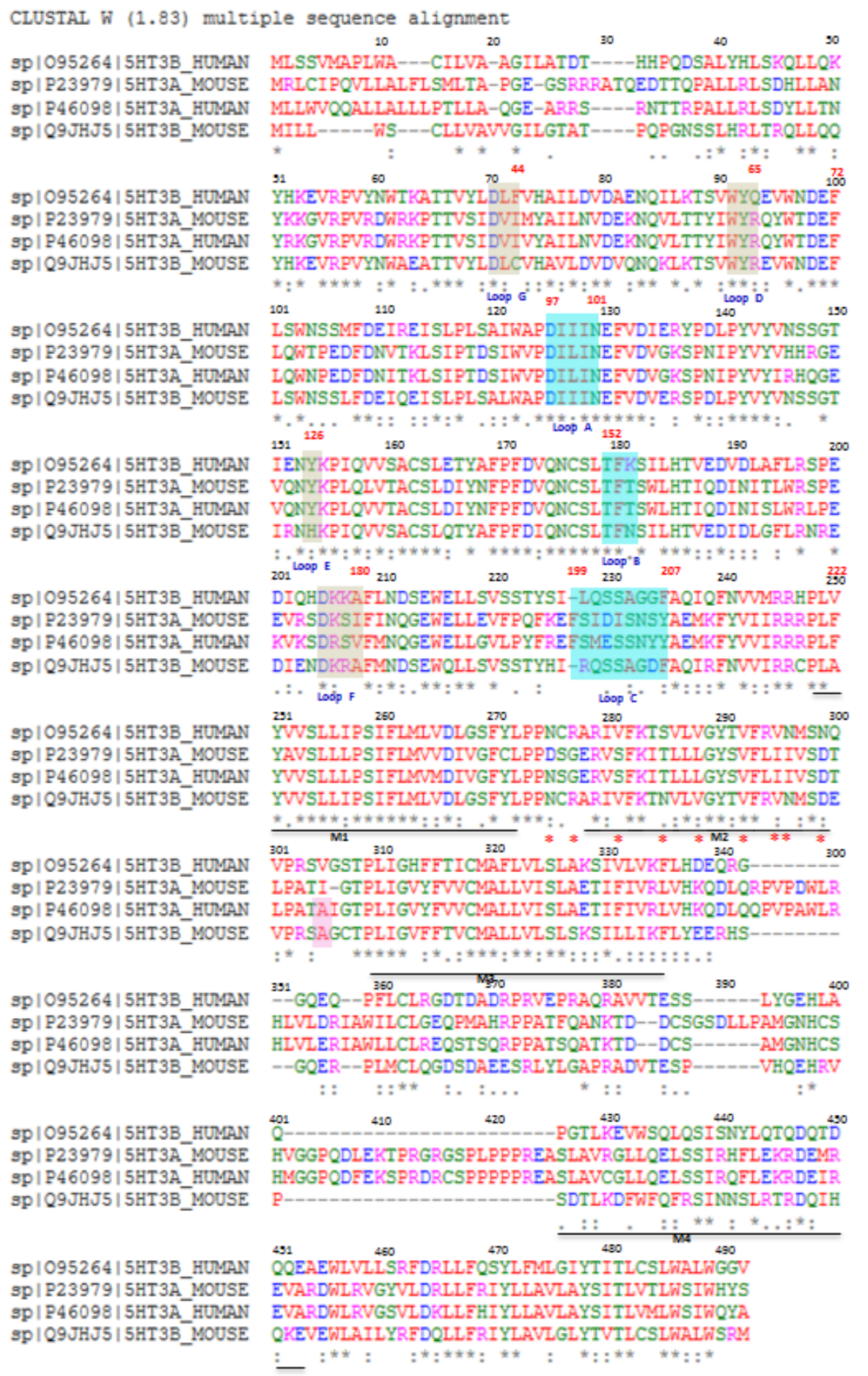

Figure 16. Sequence alignment for human and murine $5-\mathrm{HT}_{3}$ receptor subunits A and B. FASTA colouring scheme (red lipophilic; blue acidic, magenta basic, green polar). Key residues for principle subunit (blue shaded box), complementary subunit (grey shaded box); pore-facing residues of TM2 (red star), TM regions M1-M4 (underlined). 
In a saturation study performed by Walstab et al.[10], a competitive antagonist was present and likely bound at the orthosteric site. Under these conditions, due to their flexibility and relative nonspecificity for a particular binding site, the ginger compounds may bind at the allosteric site to illicit their effect since they were unable to displace GR10655. It remains to be confirmed under similar experimental conditions, whether the ginger ligands would bind in the absence of any competitive antagonist and thus allow classification as either an uncompetitive inhibitor or mixed inhibitor. A similar dual role has been observed for amide-type local anaesthetics, lidocaine and bupivacaine.[49] Structural characteristics of the ginger compounds which could contribute to their capacity to bind well in different environments are their flexibility and combination of both a degree of polarity and hydrophobic character. These structural features could enable the ginger compounds to exploit the specific complementarity at each site.

Our results could reflect the structural changes that occur in the transition from open to closed channel conformations. Serotonin binds with high affinity to the open conformation. Hassaine et al.[5], speculated that the crystal structure they produced is in the closed conformation. Thus it is possible that the overall score of serotonin was lower than what may have been observed for the open conformation. Additionally, the crystal structure depicts an A+A- subunit homomeric structure. Given the five currently identified subunits, varying degrees of binding affinity would be expected by all ligands with the concomitant changes to the binding site. Allosteric modulators are more potent in the heteromeric receptors. To test this idea in the absence of another crystal structure, work is in progress to prepare a homology model of an $\mathrm{A}+\mathrm{B}-$ and a B-A+ receptor using a three dimensional template from the current 5- $\mathrm{HT}_{3}$ receptor.

To date no 5- $\mathrm{HT}_{3}$ crystal structures exists with a ligand bound to either the serotonin binding or the allosteric site $5-\mathrm{HT}_{3}$ receptor. High resolution, three dimensional structures of other cation 
selective CYS loop receptors, such as the nicotinic acetylcholine receptor (nAChR- $\alpha 1$ ) have been published which share a high degree of structural and functional similarity to the 5-HT3 receptor. While we investigated the two key sites identified to date in this study, it is also possible that additional binding sites for allosteric regulation exist. Future studies could explore other areas of the receptor such as the transmembrane region.

We also acknowledge the following limitations. Only one crystal structure of the $5-\mathrm{HT}_{3}$ receptor is currently available and while this allows for in silico investigation of this receptor, the crystal structure was from mouse rather than human origin and not highly resolved leading to likely discrepancies in the positioning of target atoms. Attempts to address the sequence differences between species were carried out using sequence homology and it was noted that most of the key residues are well conserved. Rigid docking approaches of this kind rely on the position of the sidechain atoms. Errors of this nature impact heavily on the ability to accurately test conformational space sufficiently well to find the most realistic binding poses. The effects of the low resolution X-ray imaging has been somewhat reduced by conducting energy minimization on the target prior to docking to relieve any initial strain in the conformation of the protein although gross misplacement of atoms/residues side-chains will not be compensated for by this measure. Since some of the key binding residues have long, flexible side chains (R219, K54, R65) and thus have a high degree of mobility, docking algorithms incorporating more flexible approached would be preferable. Molecular dynamics (MD) simulations incorporating explicit solvent would also alleviate some of the limitations mentioned above.

\section{Conclusion}

In this study, we investigated the binding interactions of ginger 6G, 8G and 10G, 6S, 8S and 10S and 6DHSG, 8DHSG and 10DHSG, as well as several known competitive and non- 
competitive antagonists at the orthosteric and allosteric binding sites on the 5-HT3 receptor. Notably, the ginger compounds scored highly at both sites along with the structural analogs, capsaicin and curcumin. It has been proposed that the ginger compounds elicit their effect through an allosteric modulation of the $5-\mathrm{HT}_{3}$ receptor. Our results support this hypothesis. Within the serotonin site, a high degree of hydrogen bonding and flexibility was proposed to contribute to their high score. Additionally, they also scored higher than other non-competitive antagonists at the allosteric site. Likewise, at the allosteric site, a high degree of hydrogen bonding and flexibility likely contributed to their overall high total. The finding that the ginger compounds outscored serotonin and other competitive antagonists at the serotonin site may have a number of possible explanations. It is hoped that this work will lead to a deeper understanding of the interactions between these ginger compounds and the $5-\mathrm{HT}_{3}$ receptor and ultimately aid in the design of more potent and specific antagonists to alleviate those who suffer CINV. Until the crystal structures of either a ligand-bound murine or, the more relevant human $5 \mathrm{HT}_{3}$ receptor we continue our work to gain further insight into the nature of these interactions. 


\section{References}

1. Jordan, K.S., Judith;Jahn,Franziska;Mueller-Tidow,Carsten;Jordan,Berit, Neuropharmacology and Management of Chemotherapy-Induced Nausea and Vomiting in Patients with Breast Cancer Breast Care Basel, 2014. 9(4): p. 246-253.

2. Hsieh, R.K.C., A.;Kim,H.K.;Yu,S.;Kim,J.G.;Lee,M.A.;Dalén,J.;Jung,H.;Liu,Y.P.;Burke,T.A.;Keefe,D. M., Baseline patient characteristics, incidence of CINV, and physician perception of CINV incidence following moderately and highly emetogenic chemotherapy in Asia Pacific countries. Support Care Cancer, 2015. 23(1): p. 263-72.

3. Cubeddu, L., Serotonin mechanisms in chemotherapy-induced emesis in cancer patients. Oncology, '996. 53 Suppl 1: p. 18-25.

4. $\quad$ Pettersson, G., The neural control of the serotonin content in mammalian enterochromaffin cells. Acta Physiol Scand Suppl., 1979. 470: p. 1-30.

5. $\quad$ Hassaine, G., et al., X-ray structure of the mouse serotonin 5-HT3 receptor. Nature, 2014. 512(7514): p. 276-81.

6. Chang, Y.-C., Wu, Wen, Zhang, Jian-Liang, Huang,Yao,, Allosteric activation mechanism of the cys-loop receptors Acta Pharmacol Sin, 2009. 30(6): p. 663-672.

7. Hsiao, B., Dweck, David, Luetje, Charles W., Subunit-Dependent Modulation of Neuronal Nicotinic Receptors by Zinc. The Journal of Neuroscience, 2001. 21(6): p. 1848-1856.

8. Connolly, C.N.W., K.A. , The Cys-loop superfamily of ligand-gated ion channels: the impact of receptor structure on function Biochem Soc Trans., 2004. 32(Pt3): p. 529-34.

9. Kelley S.P., D.J.I., Kirkness E.F., Lambert J.J., Peters J.A., A cytoplasmic region determines single-channel conductance in 5-HT3 receptors. Nature, 2003. 424(424): p. 321-4.

10. Walstab, J., et al., Ginger and its pungent constituents non-competitively inhibit activation of human recombinant and native 5-HT3 receptors of enteric neurons. Neurogastroenterol Motil, 2013. 25(5): p. 439-47, e302.

11. Davies, P.A., Allosteric modulation of the 5-HT3 receptor. Current opinion in pharmacology, 2011. 11(1): p. 75-80.

12. Vitalis, B., Sebestyen, L., Sike, M., Solyom, S., Harsing, L.G., Binding characteristics of GYKI-46903, a non-competitive ligand at 5-HT3 receptors. Pharmacol. Res., 2001. 43: p. $291-299$.

13. Nelson, D., [3H]-BRL 43694 (Granisetron), a specific ligand for 5-HT3 binding sites in rat brain cortical membrane. Biochemical pharmacology, 1989. 38(10): p. 1693-1695.

14. Roila F, B.E., Tonato M, Del Favero A. , 5-HT3-receptor antagonists: Differences and similarities. Eur J Cancer 1997. 33: p. 1364-1370.

15. Van Wijngaarden I, T.M., Soudijn W. , The concept of selectivity in 5-HT3 receptor research. Eur J Pharmacol 1990. 188: p. 301-312.

16. Tyers, M.B., Bunce, K.T., Humphrey, P.P., Pharmacological and antiemetic properties of ondansetron. . Eur. J. Cancer Clin. Oncol. , 1989. 25 (Suppl. 1): p. S15 - S19.

17. Sepulveda, M.I., Lummis, S.C.R., Martin, I.L., The agonist properties of mchlorophenylbiguanide and 2-methyl-5-hydroxytryptamine on 5- HT3 receptors in N1E115 neuroblastoma cells. Br. J. Pharmacol. , 1992. 104: p. 536 - 540.

18. Downie, D.L., et al., The interaction of trichloroethanol with murine recombinant 5-HT3 receptors. British Journal of Pharmacology, 1995. 114(8): p. 1641-1651. 
19. Van Hooft, J.A., Van der Haar, E., Vijverberg, H.P.M., Allosteric potentiation of the 5HT3 receptor-mediated ion current in N1E-115 neuroblastoma cells by 5-hydroxyindole and analogues. Neuropharmacology, 1997. 36: p. 649 - 653.

20. Suzuki, T., Sugimoto, M., Koyama, H., Mashimoto, T., Uchida, I., Inhibitory effect of glucocorticoids on human-cloned 5-hydroxytryptamine3A receptor expressed in xenopus oocytes. . Anesthesiology, 2004. 101: p. 660 - 665.

21. J. Daniel Hothersall, C.M., Christopher N, Connolly, Prolonged inhibition of 5-HT3 receptors by palonosetron results from surface receptor inhibition rather than inducing receptor internalization. British Journal of Pharmacology, 2013. 169 p. 1252-1262.

22. Ryan J.L., H.C.E., Roscoe J.A., et al, Ginger (Zingiber officinale) reduces acute chemotherapy-induced nausea: A URCC CCOP study of 576 patients. Support Care Cancer, 2012. 20: p. 1479-1489.

23. Marx W, K.N., Isenring L., Is ginger beneficial for nausea and vomiting? An update of the literature. Current Opinion in Supportive and Palliative Care, 2015. 9(2): p. 189-195.

24. Suekawa M, I.A., Yuasa K, Sudo K, Aburada M, Hosoya E., Pharmacological studies on ginger. I. Pharmacological actions of pungent constituents, (6)-gingerol and (6)-shogaol. . J. Pharmacobiodyn., 1984. 7(11): p. 836-48.

25. Kim E.C., M.J.K., Kim T.Y., Lee S.J., Yang H.O., Han S., Kim Y.M., Kwon Y.G., [6]Gingerol, a pungent ingredient of ginger, inhibits angiogenesis in vitro and in vivo. . Biochem Biophys Res Commun., 2005. 335(2): p. 300-8.

26. Albena T. Dinkova-Kostova, M.A.M., Richard E. Bozak, Ronald J. Hicks, Paul Talalay, Potency of Michael reaction acceptors as inducers of enzymes that protect against carcinogenesis depends on their reactivity with sulfhydryl groups. PNAS, 2001. 98(6): p. 3404-3409.

27. Pertz H.H., L.J., Roth-Ehrang R., Elz S., Effects of ginger constituents on the gastrointestinal tract: role of cholinergic M3 and serotonergic 5-HT3 and 5-HT4 receptors.

. Planta Med., 2011. 77(10): p. 973-8.

28. Abdel-Aziz H., N.A., Petereit F., Windeck T., Ploch M., Verspohl E.J. , 5-HT3 receptor blocking activity of arylalkanes isolated from the rhizome of Zingiber officinale. Planta Med., 2005. 71: p. 609-16.

29. Abdel-Aziz, H., et al., Mode of action of gingerols and shogaols on 5-HT3 receptors: binding studies, cation uptake by the receptor channel and contraction of isolated guinea-pig ileum. Eur J Pharmacol, 2006. 530: p. 136 - 143.

30. Panahi Y., S.A., Sahebkar A., Hashemian F., Taghikhani M., Abolhasani E., Effect of ginger on acute and delayed chemotherapy-inducednausea and vomiting: a pilot, randomized, open-label clinical trial. Integr Cancer Ther, 2012. 11: p. 204-11.

31. Reeves, D.C., Sayed, Muhammed, F.R., Chau, Pak-Lee, Price, Kerry L., Lummis Sarah R., Prediction of 5-HT3 Receptor Agonist-Binding Residues Using Homology Modeling. Biocphysical Journal, 2003. 84: p. 2338-2344.

32. Longo, D.L., et al., Results of a randomized double-blind crossover trial of scopolamine versus placebo administered by transdermal patch for the control of cisplatin-induced emesis. Cancer Treat Rep, 1982. 66(11): p. 1975-6.

33. Goodford, P.J., A computational procedure for determining energetically favorable binding sites on biologically important macromolecules. J Med Chem, 1985. 28(7): p. 849-57. 
34. A. Dejoux, P.C., N. Hannick, G. Moyna, \& F.-Y. Dupradeau, AmberFFC, A Flexible Program to Convert AMBER and GLYCAM Force Fields for use with Commercial Molecular Modeling Packages. J. Mol. Model., 2001. 7: p. 422-432.

35. Sievers F., W.A., Dineen D., Gibson T.J., Karplus K., Li W., Lopez R., McWilliam H., Remmert M., Söding J.,Thompson J.D., Higgins D.G., Fast, scalable generation of highquality protein multiple sequence alignments using Clustal Omega. Molecular systems biology, 2011. 7: p. 539.

36. Pearson, W.R., Searching protein sequence libraries: comparison of the sensitivity and selectivity of the Smith-Waterman and FASTA algorithms. Genomics, 1991. 11(3): p. 635-50.

37. Russell Spitzer, A.N.J., Surflex-Dock: Docking Benchmarks and Real-World Application. J Comput Aided Mol Des., 2012. 26(6): p. 687-699.

38. Goodford, P., A computational procedure for determining energetically favorable binding sites on biologically important macromolecules. J. Med. Chem., 1985. 28(7): p. 849-857.

39. Thompson, A.J. and S.C.R. Lummis, 5-HT(3) Receptors. Current pharmaceutical design, 2006. 12(28): p. 3615-3630.

40. Trattnig, S.M., et al., Discovery of a novel allosteric modulator of 5-HT3 receptors: inhibition and potentiation of Cys-loop receptor signaling through a conserved transmembrane intersubunit site. J Biol Chem, 2012. 287(30): p. 25241-54.

41. Thompson, A.J., Verheij, H.P., de Esch, !. J. P., Lummis, S.C.R., VUF10166, a Novel Compound with Differing Activities at 5-HT3A and 5-HT3AB Receptors. The Journal of Pharmacology and Experimental Therapeutics, 2012. 341(2): p. 350-359.

42. Lummis S. C. R, T., A.J., Bencherif M., Lester H.A., Varenicline is a potent agonist of the human 5-HT3 Receptor. American Society for Pharmacology and Experimental Therapeutics, 2011. 339(1): p. 125-31.

43. Kerry L. Price, R.K.L., Chris Ulens,Sarah C.R. Lummis, Varenicline Interactions at the 5

2015. 6: p. 1151-1157.

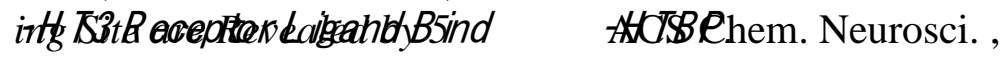

44. E. H. Juarez, F.O.-C., M. Miranda-Morales, R. Espinosa-Luna, L. M., Montano C. Barajas-Lopez, Selectivity of antagonists for the Cys-loop native receptors for ACh, 5-HT and GABA in guinea-pig myenteric neurons. Autonomic and Autocoid Pharmacology, 2014. 34: p. 1-8.

45. Taly, A., et al., Nicotinic receptors: allosteric transitions and therapeutic targets in the nervous system. Nat Rev Drug Discov, 2009. 8(9): p. 733-50.

46. Thompson, A.J., H.A. Lester, and S.C. Lummis, The structural basis of function in Cysloop receptors. Q Rev Biophys, 2010. 43(4): p. 449-99.

47. $\quad$ Del Cadia, M., et al., Exploring a potential palonosetron allosteric binding site in the 5HT(3) receptor. Bioorg Med Chem, 2013. 21(23): p. 7523-8.

48. Thompson, A.J., Recent developments in 5-HT3 receptor pharmacology. Trends Pharmacol Sci, 2013. 34(2): p. 100-9.

49. Ueta, K., et al., Local anesthetics have different mechanisms and sites of action at recombinant 5-HT3 receptors. Reg Anesth Pain Med, 2007. 32(6): p. 462-70.

50. Baenziger J, E., , Corringer P,J,, 3D structure and allosteric modulation of the transmembrane domain of pentameric ligand-gated ion channels. Neuropharmacology, 2011. 60(1): p. 116-25. 
